號入十四百二第誌墔會究研事醫堂天㮌二九三

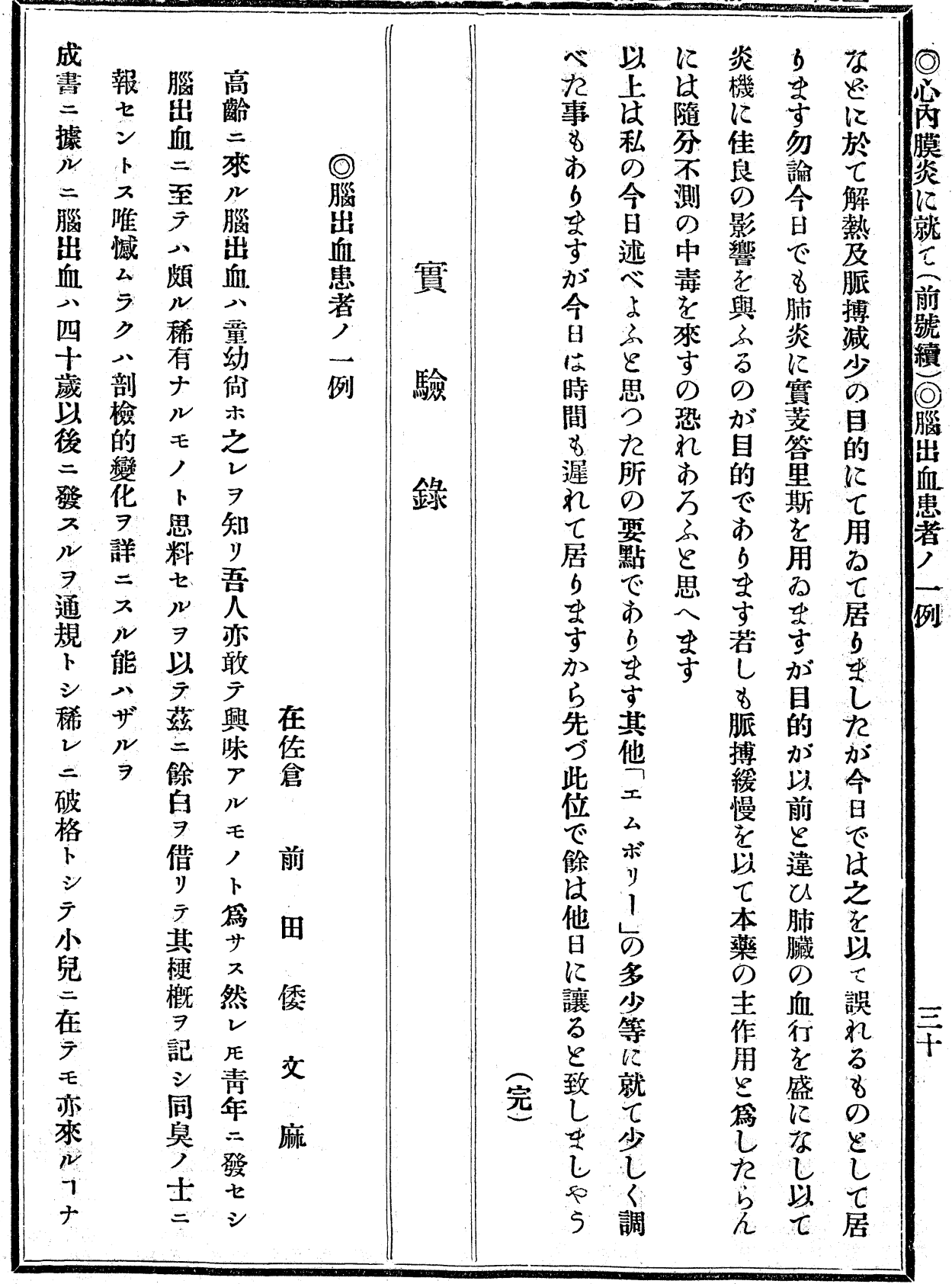


三九三 錄驗實誌雜會究研事醫堂天順

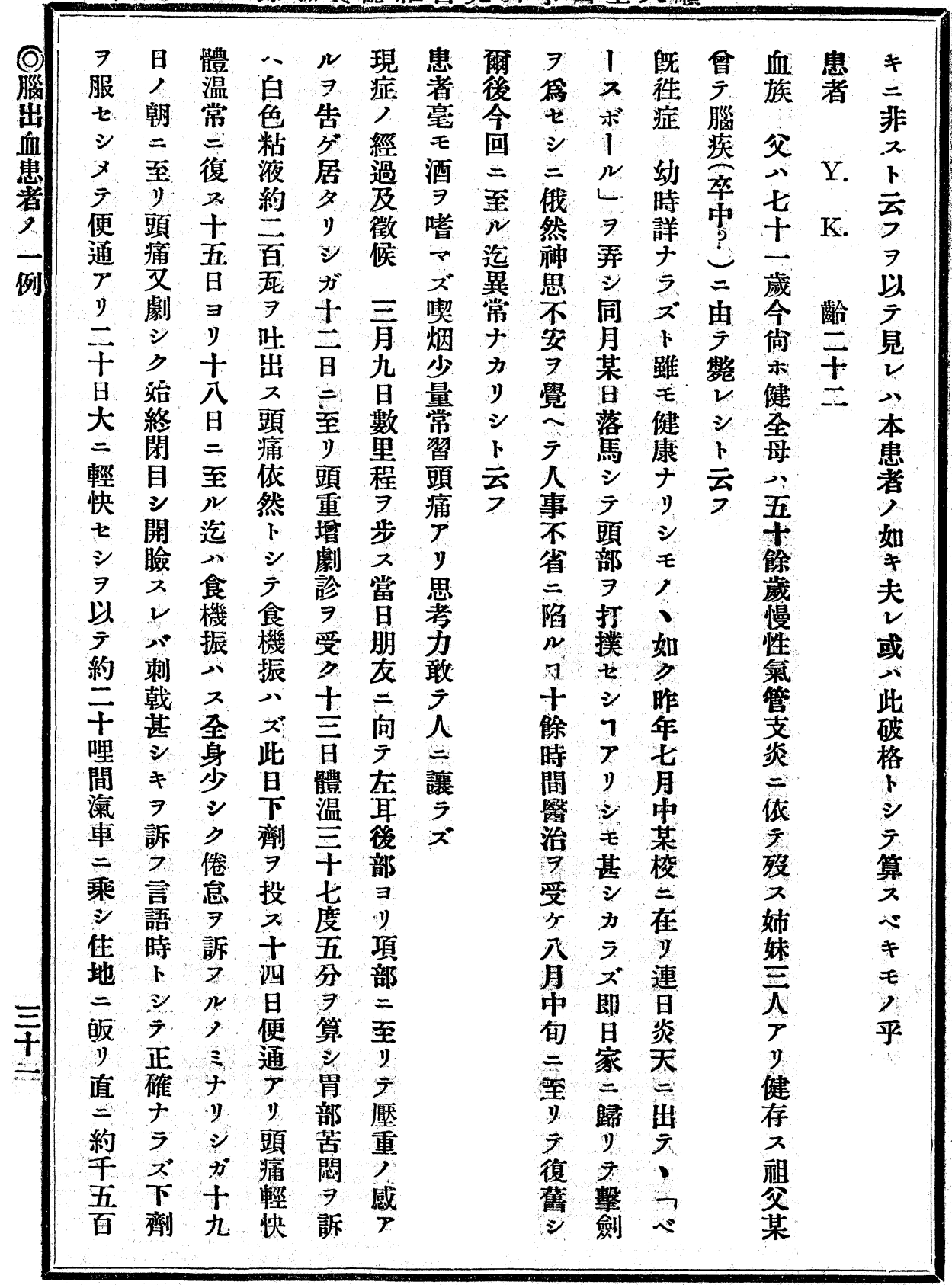


號八十四百二第誌雜會究研事醫堂天順四九三

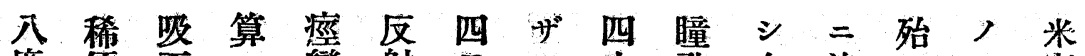

度便五 $大$ 戀射 日

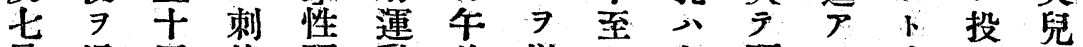

分混回韩硬動前以于左項 $三$ 全涑,

呼 シ 鼾浣直

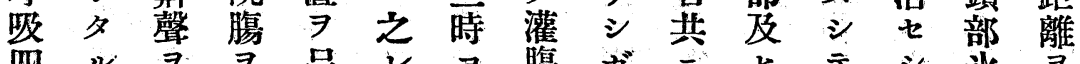

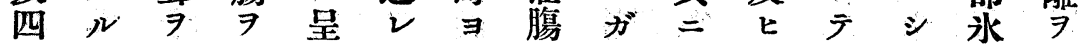

十水放 行

回液于 $₹$ 檢時施分名肢物, 法行

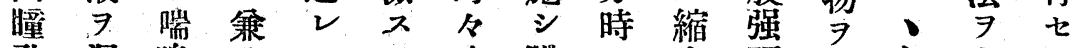

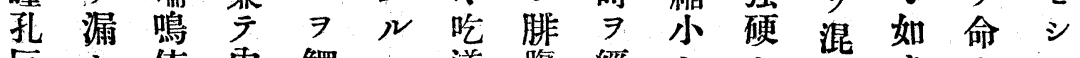

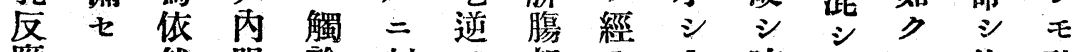

應 シ 然服診制

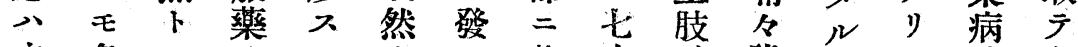

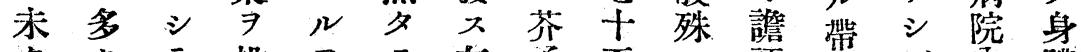

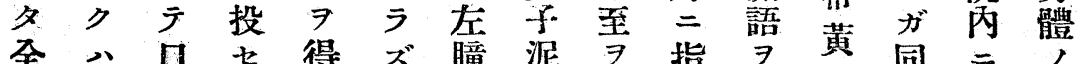

全八םセ得 $ス ゙$ 瞳 泥 $尹$ 指 $尹$ 黄同 $=$,

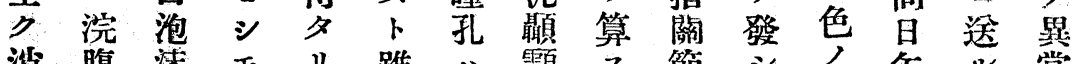

消腸 渿モり踓

失液狀䁩午モ右部体

七刀粘下前各二三 温牛撮 7 午爽感

ズ逆液作八部比水至空吐時食七

呼流 $习$ 用時共

吸七吹ナ体 $=$ 百七曲床同然振り

時シ・クシ 温殆 バ五度狀ス時傍七方

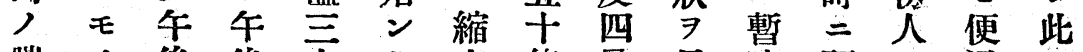

喘, 後後干卜小條分呈時頭 7 通 日

鳴、七三消,

谷如時 時 度失度 貼際呼シ 異 ビリリ

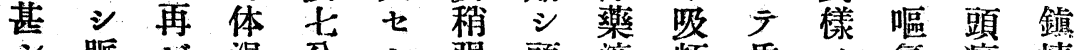

脈ビ温分シ强頭液頻昏, 氯痛靖

搏刺三三モク部 $尹$ 迫睡感 $\exists$ 减健

シ 頻戟干昇, 反水投喘狀 $ア$ 催退胃

テ 數 灌九騰、應 水七鳴

口微腸度 シ 如

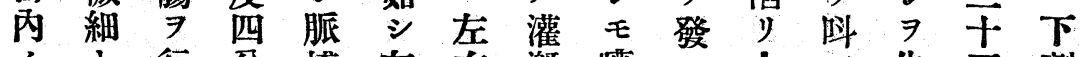

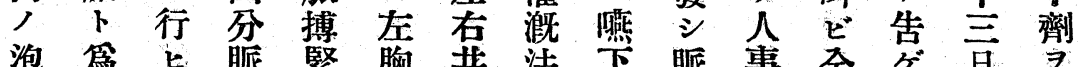

泡篇

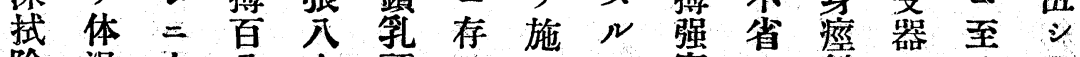

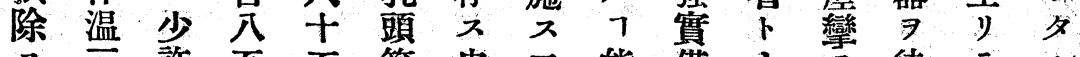

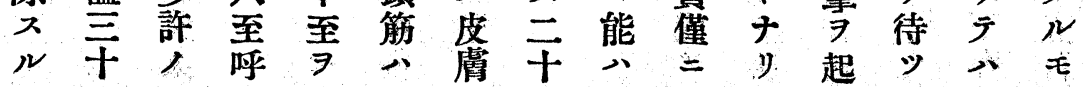




\section{五九三 錄驗實誌雜會究研事醫堂天㮌}

前附力血 $シ$ 未、ノ一疾書見狀音二

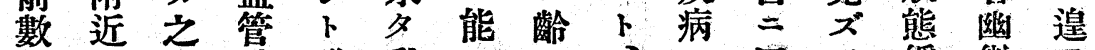
分 $v$ 壁 踓 動 $心=\square 、$ 緩 微 7

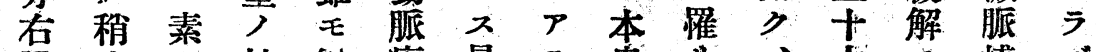
曈右 $\exists$ 抗既 瘤最

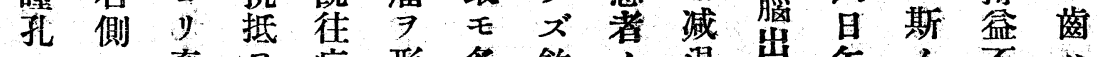

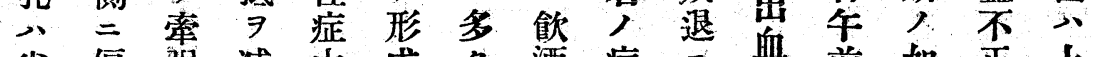

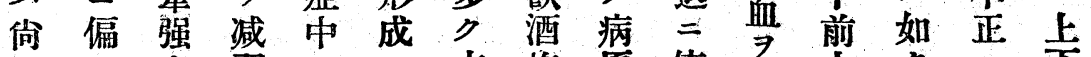

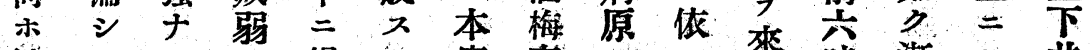

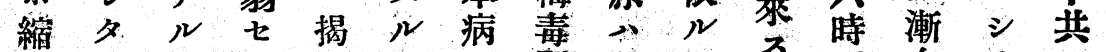

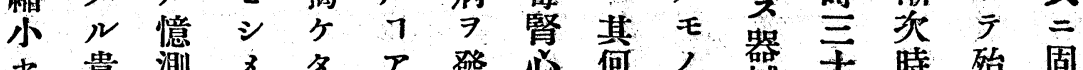

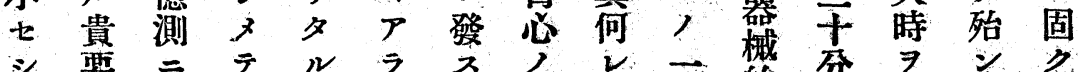

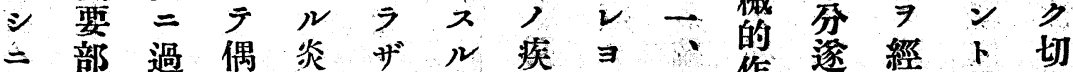

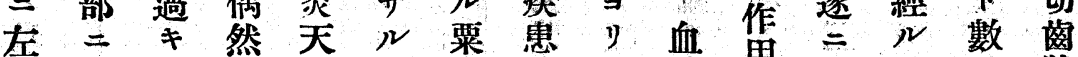
瞳 於 ズ出, 心粒 其 發管 用怘 $=7$ 狀 我而血直 $⿻$ 動他七周就臟隨, 先 大 $₹$

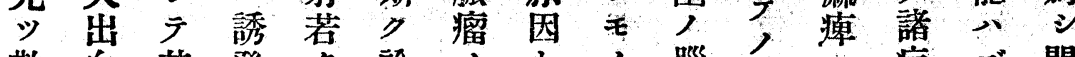
散 血 其 㖟.ク詮ノノトノ腦 學 二 症 ズ 開

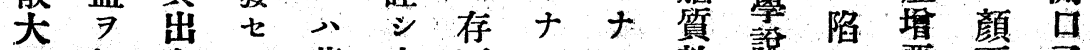

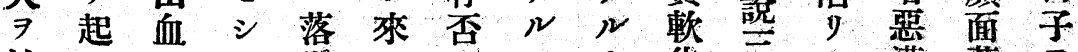
始 シ , モ駡 丈逐部, 擊心之之人年及多死腸息用

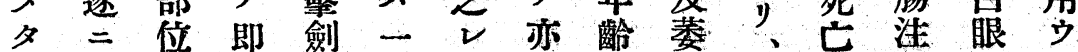

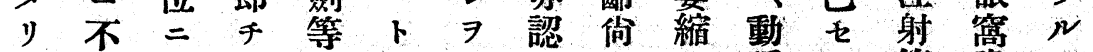
四幸至前 $;$ ～知公

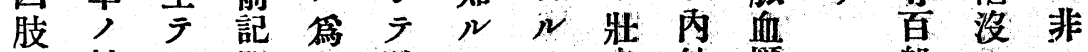

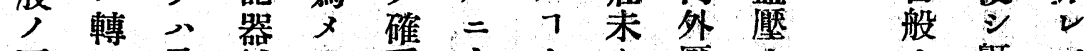

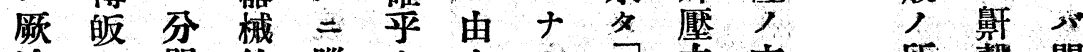

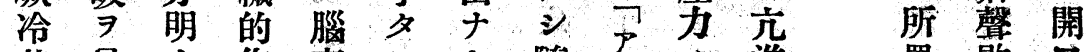
其見ナ作充 $キ \neq$ 隨

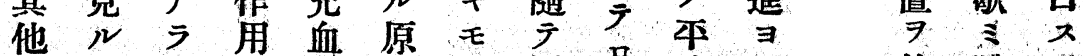

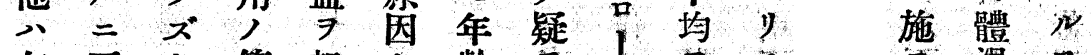

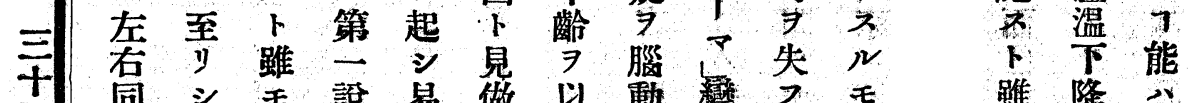
同 $シ$ 琶

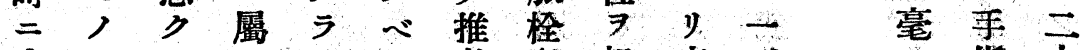
秝ナ 八ス

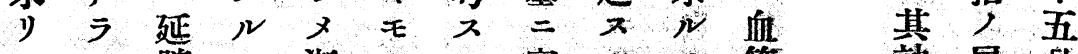

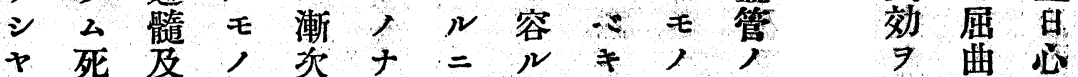


號入十四百二第誌嚾會究研事醫堂天順 坴九三

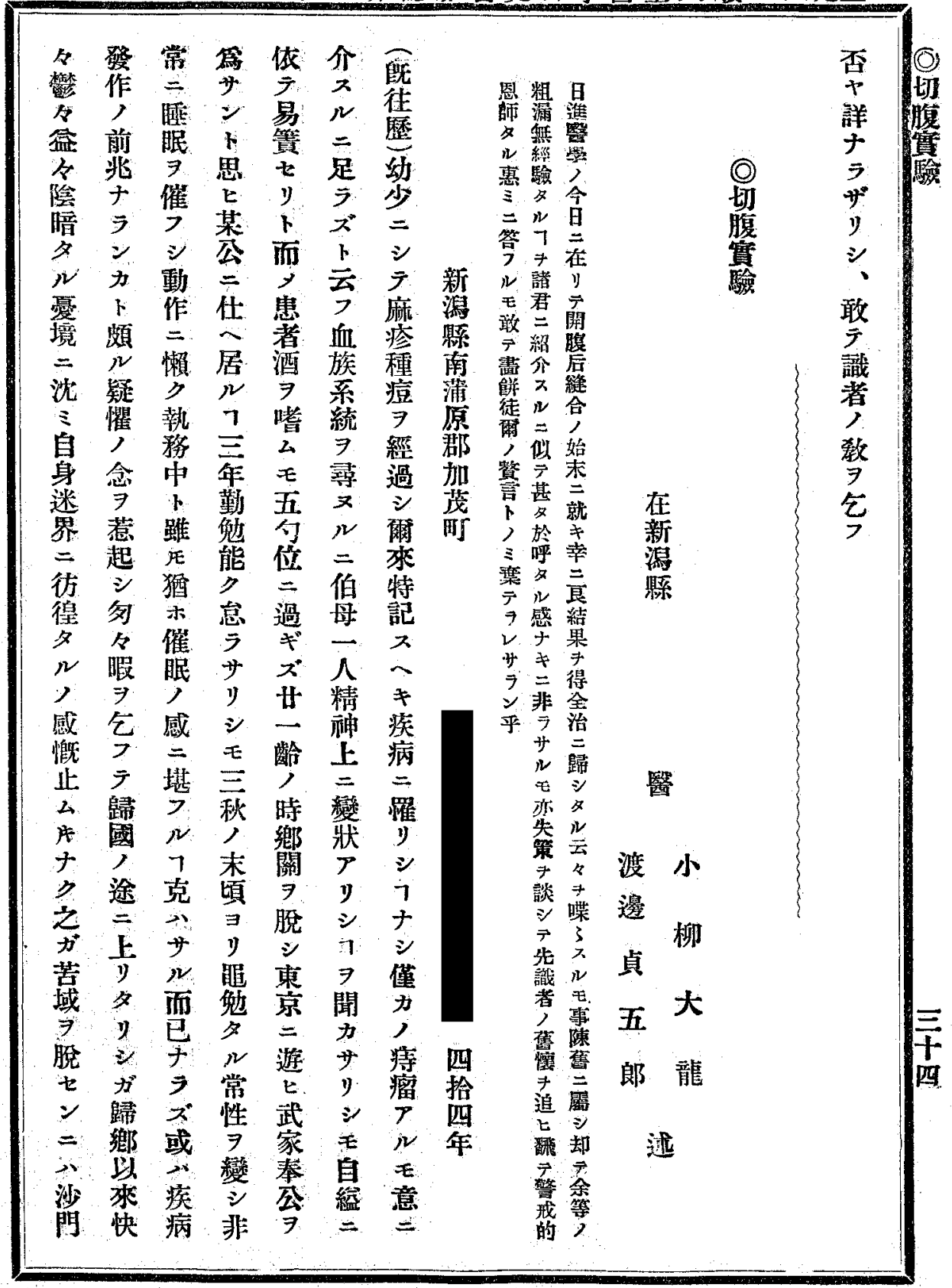

